\title{
REGIME JURÍDICO À BRASILEIRA: AS DUAS BASES DE CONSTRUÇÃO DO REGIME DE DIREITO PÚBLICO NO BRASIL
}

\author{
LEGAL SYSTEM 'A LA BRAZIL': THE TWO BASES OF CONSTRUCTION OF THE OF PUBLIC
}

LAW SYSTEM IN BRAZIL

\section{Marco Antônio Moraes Alberto*}

\begin{abstract}
Resumo:
Este artigo tem o objetivo de mapear as duas bases teóricas de construção daquilo que ficou conhecido, no Brasil, como "regime jurídico de direito público". Para tanto, identifica duas vertentes de construção desse conceito teórico que, apesar de suas diferenças metodológicas, convergem enquanto modelo doutrinário do direito administrativo brasileiro. Investiga-se, assim, como a teoria jusnaturalista (tomista) proposta por Ruy Cirne Lima se relaciona à abordagem pretensamente positivista de Celso Antônio Bandeira de Mello, e como é possível que duas inspirações epistemológicas tão diferentes compartilhem sentidos tão próximos a respeito do poder do Estado, do conceito de administração pública e da atuação administrativa na sociedade civil. Argumenta-se que as duas teorizações contêm juízos políticonormativos não triviais, que evidenciam elementos de longa duração histórica na compreensão do Estado de Direito no Brasil.
\end{abstract}

Palavras-chave: Regime jurídico. Direito público. Teoria do direito.

\begin{abstract}
:
This paper aims to map the two theoretical construction bases of what became known, in Brazil, as "Public Law System". For this purpose, I identify two shaping aspects of this theoretical concept that, despite their methodological differences, converge as a doctrinal model able to frame Brazilian Administrative Law. The author investigates how Natural Law doctrine, supported by Ruy Cirne Lima, could be related to Celso Antônio Bandeira de Mello's (supposedly) positivist view, and how possible these two very different epistemological inspirations can share central aspects regarding the State power, the public administration and the administrative enforcement in the civil society. I argue that these two theories entail non-trivial statements on normative political theory, which highlight long-term historical elements that structure the interpretation of Rule of Law in Brazil.
\end{abstract}

Keywords: Legal System. Public Law. Jurisprudence.

\footnotetext{
Doutorando em Direito do Estado pela Universidade de São Paulo. Bacharel em Direito pela Universidade de São Paulo (FDUSP). Pesquisador do Departamento de Direito do Estado da Universidade de São Paulo (DES-USP). Pesquisador bolsista da Fundação de Amparo à Pesquisa do Estado de São Paulo (FAPESP). Assistente de docência e de produção no Departamento de Direito do Estado da Faculdade de Direito da Universidade de São Paulo (FDUSP). Assessor de pesquisa jurídica na Controladoria Geral da Universidade de São Paulo (CG-USP). Professor, consultor e advogado em São Paulo. O autor gostaria de agradecer a Celso Fernandes Campilongo, Conrado Hübner Mendes, Daniel Peixoto Murata, Danielle Hanna Rached, Fernando Dias Menezes de Almeida, Floriano de Azevedo Marques Neto, Henrique Almeida de Castro, João Augusto Fernandes Stipp, João Otávio Paes de Barros, Juliana Pacetta Ruiz e Vitor Rhein Schirato pela leitura e pelos comentários a versões preliminares deste artigo, bem como pelo incentivo à sua publicação. O autor é grato à FAPESP (Processo n. 2017/13539-6). E-mail: marco.alberto@usp.br.
} 
1. Introdução: o problema do regime jurídico de direito público no Brasil

Poucos temas do direito administrativo brasileiro são tão nucleares e tão originais como a discussão do denominado "regime jurídico de direito público". Seja para infirmá-lo, seja para defendê-lo, é em torno desse suposto conceitual que parece orbitar boa parte da controvérsia doutrinária administrativista - e, de um modo mais geral, publicística - desde a redemocratização. ${ }^{1}$

Trata-se de uma disputa que está longe de ser resolvida, e que antagoniza, a partir de si, dois grandes grupos no direito público brasileiro: ${ }^{2}$ um que argumenta a existência sólida de um regime jurídico próprio do direito público, de algum modo vinculado aos atores estatais, e excludente e derrogatório do direito privado, ${ }^{3}$ e outro que procura contemporizar a apartação entre direito público e direito privado, a partir de categorias jurídicas transversais (v.g. contrato, obrigação jurídica, processo, regulação) ${ }^{4}$ ou da principiologia oriunda do constitucionalismo. ${ }^{5}$ É possível dizer, de toda maneira, que o debate doutrinário atual, no direito público brasileiro, é um debate sobre regime jurídico.

Mas o que isso significa exatamente? Ou, por que razão a discussão da teoria do direito público brasileiro haveria de estar centrada no eixo metodológico representado pelo conceito de "regime jurídico"? É buscando dar substrato para a resposta a essas questões que me proponho a examinar, sucintamente, duas teorizações brasileiras dotadas de relevância central na construção daquilo que veio a ficar conhecido e difundido como "regime jurídico de direito público".

São elas a teoria da administração pública como princípio de regência superior, impessoal e finalística da comunidade, e a teoria da supremacia e indisponibilidade do interesse público como axiomas de um "regime jurídico-administrativo". A primeira,

1 Para um balanço sobre como esse debate se constrói, entre uma perspectiva democrática-liberalizante (subjetivista, centrada nos direitos e liberdades individuais) e outra perspectiva nacional-estatizante (publicista, focada na autoridade do interesse público) a partir da redemocratização brasileira, em 1988, v. Almeida (2015, p. 401-411).

2 Esses grupos correspondem, em boa medida, aos blocos defensores de um direito administrativo ex pars populi (crítico do denominado "regime jurídico administrativo") e de um direito administrativo ex parte principis (que vê no regime jurídico de direito público um valor operacional persistente e central). Vide Marques Neto (2015). No mesmo sentido, mapeando os dois blocos de autores, v. Sundfeld (2012, p. 32-37).

3 Para essa posição, contemporaneamente, v. Di Pietro (2016) e Gabardo e Hachem (2010).

4 Nesse sentido, vide, respectivamente, as obras: Almeida (2012a), Schirato (2012), Medauar (1993) e Marques Neto (2002).

5 A linguagem de direitos, contida na Constituição, permitiu uma convergência entre diversas correntes publicistas brasileiras. Para esse ponto, v. Almeida (2015, p. 299-304). Exemplificativamente, v. Silva (2006), Barroso (2012) e Sarmento (2008). É evidente que isso dependeu da conjuntura político-jurídica, isto é, da intricada e ambiciosa costura entre policy e polity realizada na Constituição de 1988 (cf. COUTO; ARANTES, 2006). 
formulada por Ruy Cirne Lima, é fundada em uma releitura do romanismo pós-clássico pelas lentes do direito natural tomista (tardo-medieval) e moderno. ${ }^{6}$ A segunda, proposta por Celso Antônio Bandeira de Mello, parte do positivismo metodológico (e, em algum grau, jurídico) para tentar definir um horizonte de coesão para o direito administrativo, e assim justificar a atuação da administração pública. ${ }^{7}$

Malgrado as elementares diferenças existentes entre os dois projetos teóricos ${ }^{8}$ - em um sentido importante, Cirne Lima e Celso Antônio Bandeira de Mello têm referenciais epistemológicos opostos, de modo que suas doutrinas revelam-se alternativas entre si - sugere-se, neste artigo, que ambas as teorizações constituem-se como antípodas de um mesmo modo de pensar, especificamente, a relação entre Estado e administração pública, relação que é, a propósito, a relação que vem historicamente referida pela epígrafe "regime jurídico do direito público" (BEAUD, 2011, p. 11).

Argumenta-se, já em sentido conclusivo, que se é verdade que ambas as teorias revelam formas diferentes (e por vezes opostas) de tratar um mesmo "tronco comum", então é esse tronco o suposto que parece dar o tom da atual compreensão do regime jurídico de direito público, e, por corolário, enquadrar o debate da doutrina

6 Ruy Cirne Lima parte de algumas noções centrais do jusnaturalismo, tais como utilidade social enquanto expressão do bem comum ao ente impassível de gozo individual (sociedade) e vinculação prudencial da autoridade ao bem como remédio à tirania, dentre outros tópicos do catálogo de recepção do direito clássico pelo tomismo medieval, para vincar o predicado a que se vincula o sujeito que rege a comunidade. Isso não o impede, também, de partir de certos tópicos do jusracionalismo iluminista, como a vinculação finalística racional da ação individual, e a ideia, central ao movimento codificador francês, da ordem natural coextensiva à ordem legal (lois civiles dans leur ordre naturel, cf. Domat, 2019). Vide Lima (1951, p. 23 e 26-27) e Lima (2007, p. 25-26).

7 Faço a ressalva porque se é verdade que, em "Natureza e regime jurídico das autarquias", Celso Antônio Bandeira de Mello atribuía à vontade do legislador - e, portanto, ao direito posto por decisão - a definição do interesse público, suposto básico dos axiomas da "supremacia do interesse público" e da "indisponibilidade do interesse público", que informam o regime jurídico de direito público, também é verdade que, nas sucessivas atualizações de seu "Curso de direito administrativo", os referidos axiomas vêm ganhando leitura progressivamente ampliativa, servindo como parâmetros vinculantes não apenas do legislador, como do próprio Poder Constituinte, o que evidentemente compromete a positividade do regime jurídico de direito público (Vide, comparativamente, Bandeira de Mello (1968, p. 286; 2012, p. 68-69 e nota n. 9).

8 Circunstância que é reforçada pela própria conjuntura das produções dos dois autores. Cirne Lima tem o auge de sua produção científica madura entre 1940 e 1960, período de formação intelectual de Celso Antônio Bandeira de Mello, que se forma bacharel em direito em 1959, e escreve sua primeira grande obra, "Natureza e regime jurídico das autarquias", em 1968. É evidente que Cirne Lima constituiu uma importante referência teórica para Celso Antônio Bandeira de Mello (v. g. o conceito de administração pública de Cirne Lima é a base da ideia de "função administrativa" proposta pelo autor, sobretudo a título de "indisponibilidade do interesse público"). Entretanto, é inegável que Celso Antônio Bandeira de Mello, quando propõe o regime jurídico administrativo como realidade formal e normativa, tem o claro propósito de desvincular-se de pressupostos jusnaturalistas, como os mobilizados por Cirne Lima, denominando-os "realidade pré-jurídica", "exclusiva ao momento legislativo", aptas a perfazer "realidades substanciais ou infraestruturais" e "indagações sobre as funções e os fins públicos" nas quais a "ciência jurídica não deve adentrar". Para esse ponto, vale o cotejo, respectivamente, entre as p. 296-297 e 286-288 de seu "Natureza e regime jurídico das autarquias" (BANDEIRA DE MELLO, 1968). 
publicística contemporânea. Isso significa que as duas teorias assumem a forma de dois alicerces que, sem prejuízo de suas insuperáveis diferenças, são basilares à construção do "regime jurídico de direito público" originalmente brasileiro, fundamentando, portanto, a construção do "regime jurídico à brasileira", conforme pontuado no título deste trabalho. ${ }^{9}$

\section{Ruy Cirne Lima e a administração do bem comum}

Ruy Cirne Lima tem uma abordagem tão eclética quanto sofisticada da disciplina da administração pública. Dois movimentos são, contudo, centrais em seu pensamento: (i) a noção de relação administrativa, extraída de uma categoria do direito comum (a administração, em oposição à propriedade), e (ii) a qualificação propriamente pública da relação administrativa, que vincula o "regente da comunidade" (administração) à utilidade social, e, dessa maneira ao bem público. Cruzando esses dois conceitos, Cirne Lima conclui pela existência de uma "administração pública", que se traduz em uma convergência de entidades e atividades administrativas na pessoa jurídica "Estado". O regente da comunidade (a administração pública) coincidirá, portanto, com o Estado, vinculado a uma lógica de sobreposição harmônica entre lei positiva e utilidade pública. Tentar-se-a, articulando as etapas dessa construção teórica, mostrar que a conclusão a que chega Cirne Lima não é trivial, e prepara o terreno não apenas para a tese do regime jurídico de direito público proposta por Celso Antônio Bandeira de Mello, como também para a compreensão, ainda prevalente na teoria do direito público, da relação entre Estado e administração pública.

9 Ambos os autores veem no direito administrativo o núcleo do direito público, o subconjunto de onde emanam os princípios mais abstratos, mas também mais intensos, que têm a pretensão de se espraiar por todas as outras subáreas do direito público (constitucional, penal, processual, etc.). Com efeito, Cirne Lima afirma que toda a organização do Estado, seja em sua fixação positiva (direito constitucional), seja em sua dimensão de monopólio da sanção (direito penal), seja em sua executoriedade (direito processual), seja em qualquer outra faceta, volta-se à utilidade pública, que é o elemento definidor da atividade administrativa. Isso significa, portanto, que sempre que se estiver diante da organização do Estado (centro unificador da atividade administrativa), em todas as suas múltiplas dimensões, se estará diante de uma atividade administrativa, e, portanto, do direito administrativo (v. LIMA, 1951, p. 27; 1948, p. 62; 2007, p. 30). Celso Antônio Bandeira de Mello, por sua vez, refere-se ao "regime jurídico-administrativo" como sendo uma manifestação particular do "regime jurídico de direito público" (universal). No entanto, é do direito público que advém a caracterização de determinados interesses como pertinentes à sociedade, e não aos particulares individualmente considerados, de onde decorrem, por sua vez, os axiomas da supremacia do interesse público sobre o particular e a indisponibilidade do interesse público. Como o direito administrativo é o direito da função administrativa, isto é, da realização do interesse público supremo e indisponível, é ele o centro lógico de todo o direito público; sua "categoria jurídica básica" (regime jurídico administrativo) é a mesma do "direito público em geral", de modo que ele se coloca como superior e a transversal sobre todo o direito público (BANDEIRA DE MELLO, 1968, p. 292; 2012, p. 37 e 54-55). Em função disso, os dois autores tratam de modo coextensivo o núcleo do direito administrativo e núcleo do direito público em geral, orientação que reproduziu-se neste artigo. 
No que toca ao primeiro dos dois movimentos acima mencionados, o autor enfrenta o problema da definição de direito administrativo atribuindo à ideia de "administração" o papel de conceito fundamental (LIMA, 1948, p. 60). A "administração" é uma categoria relacional do direito comum europeu, que será percebida, pelo jusracionalismo iluminista (também denominado "jusnaturalismo moderno"), como uma relação jurídica que vincula determinado bem a uma finalidade racional e no tempo enquanto durar tal finalidade. ${ }^{10}$ Ela se contrapõe, portanto, à relação de propriedade, que vincula permanentemente um bem a um sujeito de direito, a um agente dotado de razão e de vontade, o proprietário. Retendo essa diferenciação do Código Napoleão (1804), Cirne Lima afirma que a administração é conceito central do direito administrativo justamente por vincular um fato ou bem a determinada finalidade, impondo-a à administração pública (LIMA, 1948, p. 60-61; 1951, p. 33). São essas finalidades que determinarão a organização administrativa e a ação administrativa (LIMA, 1948, p. 62). Importar da civilística a noção de "administração" para o direito administrativo traz, portanto, uma primeira consequência fundamental: a administração pública, e, portanto, o direito administrativo, existem apenas no interior de determinada vinculação finalística.

Surge daí, no entanto, uma dificuldade: se, na relação de administração, não há um sujeito, um agente de vontade capaz de determinar racionalmente o conteúdo de tal finalidade, como é possível proceder à vinculação finalística de um bem ou de uma situação de fato? Cirne Lima responde a essa dificuldade por meio da ideia de "impessoalidade". A administração, seja nas relações de direito privado, seja nas relações de direito público, impõe, sempre, duas condições para a garantia da impessoalidade: (i) que haja um círculo de interesses "administrados", que não se confundem (embora possam se sobrepor) aos interesses de quem os administra; e (ii) que se constitua um sujeito (administrador impessoal), reflexo da personificação jurídica do círculo de interesses administrados. Em outras palavras, diferentemente da relação de propriedade, na qual um sujeito tem o direito subjetivo de exercer seu domínio conforme seus próprios interesses, na relação administrativa há sempre um círculo de interesses impessoais (impessoalidade ad intra), e um administrador igualmente impessoal e incumbido de tutelar esse círculo (impessoalidade ad extra) (LIMA, 1951, p. 22). Administrar é, pois, agir no interesse de terceiros, e não em interesse próprio. Daí a oposição entre direito subjetivo e administração (LIMA, 1942, p. 20; 1951, p. 33).

10 Toma-se o "direito comum europeu", aqui, como o direito vigente na Europa, do século XI ao surgimento das codificações nacionais, produzido a partir da mistura de direito costumeiro, direito canônico e direito romano tal como recebido no período tardo-medieval, por glosadores, comentadores e pela escolástica. Para esse ponto, v. Schioppa (2014, p. 137-148). 
É nessa estrutura que, avançando para o seu segundo movimento, Cirne Lima introduz as diferenças que aparta a administração pública da administração privada (dos bens dos filhos, dos negócios de terceiros, da tutela, da curatela, etc.), qualificando-a como expediente especial no interior do "gênero administração" (LIMA, 2007, p. 28; 1951, p. 22). Enquanto na administração privada, pela própria diversidade das relações civis, a administração é dispersa e múltipla, fazendo surgir posições administrativas difusas, episódicas e variadas entre os agentes privados, na administração pública a administração é regular e permanente, originando um núcleo central unitário, o Estado, incumbido de coordenar e unificar todas as atividades administrativas (LIMA, 1948, p. 59; 1951, p. 27). É dizer: se na administração privada o reflexo ad extra da impessoalidade é a contração, por agentes privados, de posições jurídicas específicas e momentâneas (pai, mãe, tutor, curador, gestor de negócio, etc.), na administração pública o reflexo ad extra da impessoalidade é o próprio Estado, pessoa jurídica que assume a função de administrar "o círculo máximo de interesses na sociedade politicamente organizada" (LIMA, 1951, p. 22).

Essa diferença não responde, contudo, qual é a fonte que rege a relação administrativa, apta a desempenhar papel análogo ao da vontade do proprietário em uma relação de domínio. Cirne Lima apresenta, então, uma segunda diferença entre administração pública e administração privada, e é aí que se evidencia, definitivamente, sua filiação jusnaturalista. Nesse passo, o autor afirma que, diferentemente da administração privada, na qual os pactos envolvendo os círculos de interesses dos administrados são contingentes, na administração pública os pactos entre administradores e administrados têm conteúdo necessário (LIMA, 1951, p. 25), coextensivo tanto com a "ordem jurídica positiva vigente", quanto com o "ordenamento jurídico da sociedade como um todo" (LIMA, 1951, p. 22).

Ora, a consequência lógica dessa construção é a de afirmar um conteúdo necessário à atuação administrativa, que não se confunde, portanto, com a mera positividade (contingente) do direito. Isso é fundamental para compreender a noção de atuação administrativa presente no pensamento do autor. Com efeito, se a atuação administrativa tem um conteúdo necessário (e não contingente), as normas que atribuem espaços decisórios à administração pública (discricionariedade) são cogentes, e não dispositivas (LIMA, 1951, p. 20-21). Ou seja: os pactos envolvendo o círculo de interesses dos administrados, círculo tutelado pelo Estado, não são disponíveis, ainda que pelos próprios titulares de tais interesses (os indivíduos, os administrados).

Enquanto "pactos", os atos administrativos emanam de um poder (administrativo), e encontram a fonte de seus efeitos naquilo que é concretamente querido pela administração pública. Mas - e esta é a chave epistemológica da teorização proposta pelo autor - essa dependência que os atos administrativos têm de uma "vontade da 
administração" não é mais do que a dependência de uma "vontade" que é condicionada, em sua base, por uma ordem jurídica, positiva e suprapositiva, a que a administração pública se vincula. A administração pública, e, por corolário, o Estado, não cria direito. Daí a ideia de que administração pública não cria, mas revela o direito (LIMA, 1951, p. 21), o que significa dizer que o Estado não produz, mas sim enuncia o direito (LIMA, 2007, p. 32). Não existe, assim, um “poder administrativo", mas um dever administrativo.

Trata-se da tese do poder-dever da administração pública, que celebrizou Cirne Lima na história do direito público brasileiro. Segundo essa tese, a atuação administrativa advém não de um artifício de vontade (interesse subjetivo, seja do administrador, seja dos administrados), mas sim de um dever prescrito no interesse da finalidade (sempre impessoal) a que toda a atividade administrativa se vincula (LIMA, 1951, p. 21). O conteúdo da atuação administrativa é necessário. Ele é revelado a partir de uma ordem positiva (lei), que está, por sua vez, vinculada a uma "plenitude lógicojurídica" oriunda de uma “ordem jurídica suprapositiva” (LIMA, 1951,p. 21). É essa ordem jurídica suprapositiva, coincidente com o direito natural, ${ }^{11}$ que é revelada pela atuação da administração pública, seja quando a administração atua vinculada à lei (lei positiva como determinação concreta do direito natural), seja quando atua discricionariamente, em paralelo à lei, mas igualmente vinculada ao direito natural. ${ }^{12}$

Daí se compreende a ideia, já mencionada, da necessidade de total coextensão entre o círculo de interesses dos administrados (círculo máximo na sociedade politicamente organizada) e o conteúdo da atuação administrativa. Essa ideia se revela, portanto, uma sofisticada interpretação da clássica vinculação hierárquica entre o conteúdo do direito natural (superior e condicionante) e o conteúdo do direito positivo (inferior e condicionado), lugar-comum do jusnaturalismo.

Se o conteúdo da atuação administrativa é necessário, nos termos acima definidos, o conteúdo normativo dos pactos envolvendo os interesses dos administrados é, simultaneamente, tanto irrenunciável e ilimitável por arbítrio da administração pública,

11 O "direito natural" pode ser definido como conjunto de doutrinas que tenham a pretensão de criar duas ordens normativas distintas, uma positiva, e outra natural. Nas teorias ditas "jusnaturalistas", a ordem positiva é contingente, enquanto a natural, necessária. A positiva é inferior e condicionada, enquanto a natural, superior e condicionante. A positiva decorre da decisão da autoridade política ordinária, enquanto a natural decorre da natureza, sendo objeto de determinação ou dedução lógica pela razão humana. Para essas distinções, v. Troper (2008, p. 20-27).

12 Cirne Lima chega inclusive a citar o célebre paralelo entre ato administrativo/Poder Executivo e lei/Poder Legislativo cunhado por Oto Mayer. Mas, se para Mayer a fonte comum de ambos é a ordenação positiva, constitucional, da política pelo direito (Rechtsstaat), para Cirne Lima, que cunha sua teoria na recepção tardo-medieval (tomista) do direito romano justinianeu, essa fonte comum não é o ordenamento positivo, mas sim a plenitude lógico-jurídica da ordem natural (lex naturalis, de São Tomás de Aquino), cujas determinações se fazem ver tanto na lei positiva como no ato administrativo discricionário. Para esse ponto, vide, comparativamente, Mayer (1949, p. 67-85) e Tomás de Aquino, trad. Loyola 2005, questão 90. 
quanto indisponível pelos particulares titulares dos interesses tutelados. ${ }^{13}$ Não se está, afinal, no campo da vontade (seja dos administradores, seja dos administrados), mas no campo do bem comum, suposto racional externo ao direito, que o vincula e condiciona (suprapositividade do direito natural). Invertendo a conhecida fórmula hobbesiana, veritas, non auctoritas, facit legem. ${ }^{14}$

O bem comum, e não a lei positiva, que é dele mera determinação, é o código que rege a administração pública, por meio da noção de "utilidade pública". Isso porque o bem comum não pode ser imediatamente fruído pela sociedade, ente que não é dotado de sensibilidade, mas apenas por indivíduos singularmente considerados. Estes indivíduos encontram, contudo, utilidade na ordenação da comunidade para o bem comum, podendo então fruir tal bem, mediatamente, pela via da disposição racional da comunidade em que se inserem. ${ }^{15}$ É por isso que a utilidade pública pode ser definida como a "expressão orgânica do bem comum" (LIMA, 2007, p. 25), sendo o elemento que confere ao direito administrativo o caráter de disciplina jurídica autônoma e o status de um direito especial (LIMA, 2007, p. 24 e 27-28). Ademais, como o Estado, por sua impessoalidade ad extra diante do círculo de interesses da sociedade politicamente organizada, é a pessoa jurídica incumbida de coordenar e unificar as atividades administrativas, cabe a ele, com exclusividade, a mensuração da utilidade pública (LIMA, 1951, p. 24). É em razão disso que o direito administrativo detém hierarquia (derrogatória) sobre o direito comum (privado) (LIMA, 1951, p. 24), e que o Estado atua como ente soberano, apto a subordinar os administrados (LIMA, 2007, p. 33).

Sintetizando tais características, é possível dizer que quando os direitos e obrigações (decorrentes da posição hierárquica e subordinante da administração pública) se concretizam em uma atividade do Estado, está-se diante do direito administrativo (LIMA, 2007, p. 34). Assim, o regime jurídico de direito público pressupõe a existência do Estado como pessoa jurídica (LIMA, 1958, p. 27), circunstância que confere à administração pública suas prerrogativas de superioridade sobre os indivíduos (sujeição especial) e de derrogação (exorbitância) do direito comum. ${ }^{16}$

13 Os atos administrativos, em Cirne Lima, conservam sempre seu caráter pactual, porquanto digam respeito a interesses fruíveis individualmente, o que os subsume à categoria da vontade individual (LIMA, 1951, p. $20 ; 2007$, p. 25).

14 Outro tema caro ao tomismo, Cirne Lima defende a determinatio da lei natural pela lei positiva (LIMA, 1951, p. 23).

15 A divisão entre utilidade e gozo do bem comum também faz o autor remontar a São Tomás de Aquino. Ver, a esse respeito, Lima (1951, p. 26) e Lima (2007, p. 24).

16 Cirne Lima nominalmente cita a tese da sujeição especial defendida pela escola institucionalista alemã (Jellinek, Mayer, Forsthoff), segundo a qual a pessoa jurídica estatal, sendo superior às pessoas dos indivíduos, detém a prerrogativa de exercer sobre os administrados o poder administrativo decorrente (prerrogativa) de sua soberania (LIMA, 2007, p. 33). 
Dessa maneira, na construção de Cirne Lima, a utilidade pública como diretivo (drive) da comunidade política importa a constituição de um Estado, que viabiliza a administração pública ao viabilizar uma atuação especial, derrogatória, hierárquica e apta a subordinar os administrados. Só existe, pois, administração pública no interior da pessoa jurídica estatal, pois só ele tem potência, por sua impessoalidade e por sua soberania, para mensurar e realizar a utilidade pública. Esse drive, produzido a partir de uma tentativa de síntese entre a lógica do direito natural e a teoria do Estado como pessoa jurídica com vontade soberana, conduz então a um regime específico, no qual há, de um lado, um regente da comunidade, ocupante de posição superior incontrastável (superiorem non recognoscens ${ }^{17}$ ), que é, contudo, vinculado ao bem público, na acepção de "utilidade pública", que é "juíza de suas decisões" (ipse populus qui ipsum officialem fecit ${ }^{18}$ ).

É evidente que ao não contemplar na lei positiva, nos arranjos institucionais participativos, no controle legal como um todo, ou mesmo na constituição positiva de um governo, a fonte e o fundamento da administração pública, Cirne Lima pressupõe - e coerentemente o faz - uma feliz coincidência ("coextensividade") entre o bem comum, dado da ordem suprapositiva, e a tutela concreta, pelo Estado, sempre em sentido de "pessoa jurídica soberana", do círculo de interesses superiores da sociedade politicamente organizada (mensuração da utilidade pública). ${ }^{19}$

No entanto, Cirne Lima deixa o caminho aberto para uma via que conduz diretamente a uma estrutura conceitual de legitimação da autoridade administrativa exorbitante e impositiva - pelas finalidades atribuídas socialmente ao Estado, ainda que isso, levado às últimas consequências, comprometa a própria ideia de vinculação do direito positivo ao direito natural. Seria possível, no entanto, levar essa estrutura de legitimação, esse regime de regência da comunidade, às suas consequências extremas, cancelando as premissas de direito natural aí envolvidas, e assim emancipar-se da frágil e escorregadia necessidade de coincidência conteudística entre bem comum e atividade administrativa? Esse é precisamente o desafio que Celso Antônio Bandeira de Mello tomou para si.

\section{Celso Antônio Bandeira de Mello e o regime jurídico-administrativo}

Celso Antônio Bandeira de Mello define regime jurídico como categoria básica, que permite, por meio de um conjunto sistematizado de princípios e regras dedutíveis da experiência sensível (empiricamente verificável), dar identidade a uma

\footnotetext{
17 Em uma tradução livre, "que não reconhece [poder] superior”.

18 Em uma tradução livre, "o povo é, seu regente faz".

19 A autoridade que não age com justiça, em São Tomás, converte-se em tirania, contra a qual não existe direito de resistência, apenas castigo no plano transcendental (TOMÁS DE AQUINO, 2005, questão 92).
} 
disciplina jurídica autônoma (BANDEIRA DE MELLO, 2012, p. 53-54). Esse enlace é feito em um plano empírico verificável, de modo que o "regime" parte sempre da observação dedutiva de uma realidade positiva. ${ }^{20}$

Desse objetivo geral decorrem os conhecidos "atributos" do regime jurídico administrativo: (i) aplicabilidade (o regime jurídico nasce de uma necessidade prática dos juristas de aplicação prática do sistema jurídico vigente, o que blinda a ciência do direito público de conceitos "metajurídicos" ou "extrajurídicos") (BANDEIRA DE MELLO, 1968, p. 286; 2012, p. 90); (ii) cientificidade (a compreensão das "normas, relações e efeitos jurídicos" de direito público pressupõe sua submissão a um regime jurídico, que contenha, positivamente, o seu conteúdo normativo) (BANDEIRA DE MELLO, 1968, p. 284); (iii) generalidade (o regime jurídico detém é amplo e abstrato, dele sendo dedutíveis logicamente normas progressivamente mais específicas e particularizadas) (BANDEIRA DE MELLO, 1968, p. 312; 2012, p. 92); (iv) positividade (diferentemente da natureza, aí incluído o direito natural, as normas jurídicas são livremente determinadas pelo legislador, donde sua mutabilidade: o regime jurídico é um instrumento formal do legislador, que o permite definir determinadas hipóteses fáticas como normas, qualificando-as no interior de um regime jurídico) (BANDEIRA DE MELLO, 1968, p. 287-288; 2012, p. 31); e (v) delimitação metodológica de campo (o regime jurídico delimita seu campo tanto em relação à mera descrição dos traços contingentes de pessoas ou institutos circunscritos ao campo quanto em relação à estruturação política das normas pelo legislador) (BANDEIRA DE MELLO, 1968, p. 282 e 285; 2012, p. 93).

Dado o profundo enraizamento do regime jurídico-administrativo, tal como definido por Celso Antônio Bandeira de Mello, na realidade positiva, no direito positivo - afinal, sua função elementar é a delimitação objetiva e formal das funções do Estado, a partir do tratamento normativo a elas conferido pelo legislador - seria de se esperar que a delimitação de conteúdo desse "conjunto normativo" fugisse completamente dos referenciais de Cirne Lima, tão carregados que são no direito natural (BANDEIRA DE MELLO, 1968, p. 286-287; 2012, p. 32-33). Não é, entretanto, o que acontece. E isso começa a ficar claro a partir da própria pergunta lançada por Celso Antônio Bandeira de Mello, que é precisamente a mesma de Cirne Lima: qual é o "quid" do direito público, o objeto que o torna o que ele é, diferenciando-o, por exemplo, de outros ramos do direito? (LIMA, 1951, p. 21; BANDEIRA DE MELLO, 1968, p. 260).

Não apenas a pergunta é a mesma, Celso Antônio Bandeira de Mello se vale do próprio Cirne Lima para definir o direito administrativo como ramo do direito público

20 Daí porque Celso Antônio Bandeira de Mello se utilize da noção epistemológica kantiana de "juízo analítico", isto é, aquele que se identifica à decomposição (analítica) dos predicados enlaçados a determina sujeito na realidade observável (BANDEIRA DE MELLO, 1968, p. 292 e nota n. 5). 
ocupado com a disciplina da função administrativa, entendida como "administração de bens de terceiros", feita por quem, diferentemente do proprietário, não pode dispor livremente sobre o que possui (BANDEIRA DE MELLO, 1968, p. 296-297; 2012, p. 37).

Prossegue Celso Antônio Bandeira de Mello: como o regime jurídicoadministrativo é aquele que concerne à função administrativa, ele precisa assumir como axioma a indisponibilidade do interesse público, na dupla acepção ("dupla proteção") que já aparecia em Cirne Lima (BANDEIRA DE MELLO, 1968, p. 292). O administrador não pode definir arbitrariamente, sem qualquer limite, nem deixar de definir o interesse público. Por seu turno, o administrado, individualmente considerado, não pode dispor sobre seu interesse, tutelado pela administração (BANDEIRA DE MELLO, 1968, p. 297).

Nas duas teorizações (Cirne Lima e Bandeira de Mello) é, pois, da indisponibilidade dos interesses públicos que advém a base normativa da administração pública. Entretanto, se em Cirne Lima essa vinculação se dá a uma ordem suprapositiva identificada ao bem comum, ${ }^{21}$ em Celso Antônio Bandeira de Mello tal vinculação se dá sempre a uma ordem positiva, exatamente pela recusa ao jusnaturalismo que está inscrito em seu projeto de seu regime jurídico de direito público.

Daí a existência de uma diferença significativa entre as duas construções teóricas: se Cirne Lima assume a possibilidade de paralelismo hierárquico entre lei e ato administrativo, ambos igualmente condicionados pelo direito natural, Celso Antônio Bandeira de Mello, cancelando a componente jusnaturalista do esquema de Cirne Lima ("bem comum"), acaba por condicionar toda a atividade administrativa à legalidade estrita (BANDEIRA DE MELLO, 1968, p. 299; 2012, p. 78-79). É dessa maneira que, em sua teoria, a infralegalidade assume o papel de predicado fundamental da função administrativa (BANDEIRA DE MELLO, 2012, p. 36).

No entanto, não é apenas na rubrica da "base normativa" que o regime jurídico administrativo de Bandeira de Mello se revela uma antípoda do regime de ordenação do bem comum proposto por Cirne Lima. O modo de atuação do Estado também acaba sendo análogo nas duas construções teóricas, ainda que por razões metodológicas diversas.

Se em Cirne Lima o Estado ordena e unifica a atividade administrativa, por ser o único capaz de realizar (com suas prerrogativas) e mensurar (pela régua da impessoalidade) a utilidade pública, em Celso Antônio Bandeira de Mello é o regime jurídico que permite o enquadramento das normas jurídicas administrativas, das relações jurídicas administrativas, e dos efeitos jurídicos administrativos no Estado. E aqui está uma das passagens mais importantes de toda a teoria de Celso Antônio Bandeira de Mello,

${ }_{21}$ Mediata ou imediatamente, a depender do perfil vinculado ou discricionário do ato administrativo. 
uma ligação que normalmente passa despercebida pelo direito público brasileiro. Normas, relações e efeitos só se tornam "administrativos" porque relativos à administração pública em sentido formal. E essa "administração pública em sentido formal" corresponde à “organização administrativa do Estado” (BANDEIRA DE MELLO, 1968, p. 291).

O raciocínio é simples. No Estado, encontra-se a organização formal da administração pública. Por organização formal da administração pública entende-se o conjunto de pessoas jurídicas formalmente integrantes da burocracia estatal. E o regime jurídico administrativo tem por núcleo aglutinador a administração pública em sentido formal, por extensão, o Estado (BANDEIRA DE MELLO, 1968, p. 290).

É nesse movimento que Celso Antônio Bandeira de Mello interpõe o conceito de administração pública, cuja função metodológica é a de correlacionar Estado e regime jurídico administrativo. Ao fazer isso, ele estabelece uma identificação - que não será superada no direito público brasileiro - entre Estado e administração pública formal (burocrática). Essa identificação limita o objeto do regime administrativo ao âmbito da administração pública formal, caracterizado pela hierarquia e pela disciplina. O conteúdo do direito administrativo é, então, vinculado em sua base um postulado de superioridade da administração pública sobre os administrados, e de sobreposição do "Estado" sobre o direito comum, de onde virá a derrogabilidade do direito privado pelo direito público, intrinsecamente exorbitante.

Elementos normativos ingressam no conceito de "Estado" a partir de seu enquadramento (legal positivo) na organização administrativa. O enquadramento legal positivo desempenha, na obra de Celso Antônio Bandeira de Mello, papel análogo ao desenvolvido pela utilidade pública no pensamento de Cirne Lima. Em ambos os casos, há um suposto normativo (utilidade social como dimensão do bem comum em Cirne Lima, ato de vontade do legislador em Celso Antônio Bandeira de Mello), que, ao enquadrar determinada atividade no conceito de administração pública, enquadra-o também no conceito de Estado, por sua vez tomado como pessoa jurídica soberana.

\section{As duas linhas do "regime jurídico à brasileira"}

Argumentou-se que as duas teorias, que procurou-se analisar nos dois tópicos precedentes, constituem-se como antípodas. Enfrentemos esse ponto. Ruy Cirne Lima e Celso Antônio Bandeira de Mello parecem oferecer o mesmo "modelo doutrinário" de regime administrativo, ainda que percorram caminhos notavelmente diferentes. ${ }^{22}$

As duas teorias constituem-se como antípodas na medida em que, partindo de fundamentações mutuamente excludentes (jusnaturalismo e positivismo jurídico),

\footnotetext{
22 Para o conceito de "modelo doutrinário" que se utilizou aqui, v. Jamin e Melleray (2018).
} 
chegam ao mesmo raciocínio prático, permeado por duas etapas lógicas: (i) uma atividade administrativa sempre culmina em uma atividade do Estado; (ii) essa atividade, valendose do seu enquadramento no arquétipo soberano do Estado, deve ser desenvolvida em um regime próprio, a altura desse arquétipo, um regime portanto marcado pela superioridade hierárquica, pela sujeição especial e pela exorbitância do direito comum. ${ }^{23}$

Note-se, no entanto, que Celso Antônio Bandeira de Mello leva às últimas consequências a ideia de legitimação da atividade administrativa pela atribuição social de finalidades públicas. Seu foco nas "fontes sociais" de tais finalidades o faz rejeitar o jusnaturalismo, que, na estrutura pensada por Cirne Lima, detinha uma função de controle moral da atividade administrativa, procurando neutralizar o poder superior soberano, incontrastável, titularizado pela administração pública (superiorem non recognoscens).

Ao eliminar, contudo, o pressuposto da "utilidade pública" (ipse populus qui ipsum officialem fecit), do binômio de Cirne Lima, Celso Antônio Bandeira de Mello deixa "solto" o outro termo do equilíbrio binomial, que é o poder administrativo. O binômio, definido nos termos de uma vinculação do poder ao bem comum, assume a forma de monômio, em que se vincula o poder ao poder, uma vontade à outra vontade, a intenção do administrador à intenção do legislador, o interesse individual ao interesse público. Um jogo, portanto, entre interesses. E esse interesse público não será, de forma alguma, revelado a partir da lei natural, no âmbito de uma relação administrativa com o particular, mas criado intencionalmente pelo legislador (em segundo grau, pela administração) e imposto, vertical e unilateralmente, ao particular (BANDEIRA DE MELLO, 2012, p. 56 e nota n. 37).

Com efeito, a supremacia do interesse público - o outro axioma do regime jurídico administrativo, ao lado da indisponibilidade - designa uma tensão entre vontades tidas por logicamente diferentes: a vontade que está na base do interesse egoísta do indivíduo singularmente considerado (interesse inferior) e a vontade que está na base do interesse do indivíduo enquanto partícipe da sociedade (interesse superior). Essa relação superior/inferior é meramente operacional, e se baseia na posição privilegiada (supremacia) da administração pública nas relações com os particulares, predicando-lhe

23 A constatação desse raciocínio prático em duas etapas é particularmente reforçada quando se observa que Celso Antônio Bandeira de Mello, assim como Cirne Lima, segue a tópica da escola institucionalista alemã, especialmente no que toca à compreensão do Estado como pessoa jurídica dotada de um poder de império (Mayer), incapaz de subordinar-se ao direito comum (privado). Em razão disso, seriam marcas distintivas e exclusivas da administração pública (e, portanto, do regime jurídico administrativo), (i) o poder de império em nome próprio; (ii) sujeição ao controle de tutela (estrutura hierárquica, ainda que imprópria); e (iii) enquadramento formal na organização administrativa (personalidade jurídica de direito público) (BANDEIRA DE MELLO, 1968, p. 322). 
verticalidade e unilateralidade (BANDEIRA DE MELLO, 1968, p. 295-296 e 317; 2012, p. 71-72).

Não fosse meramente operacional, ou seja, fosse a supremacia do interesse público um conceito dotado de dimensão ontológica, seria incoerente todo o enraizamento pretensamente positivo da noção de regime jurídico de direito público. É em razão disso que não existe identidade específica entre a supremacia do interesse público, definida por Celso Antônio Bandeira de Mello, e a obra de Cirne Lima. No interior de um esquema, como o de Cirne Lima, em que tanto o gozo individual como a utilidade pública sejam, ambos, dimensões do bem comum, não há espaço para a distinção, senão contraposição, entre "interesse público" e "interesse privado", ao menos não nos termos (volitivos) pressupostos pela tese da supremacia do interesse público (Bandeira de Mello).

E é essa distinção lógica público/privado que permite a legitimação da imposição unilateral e vertical da vontade da administração sobre a vontade do particular. Ao adensar o peso das fontes sociais em um conceito herdeiro do jusnaturalismo, Celso Antônio Bandeira de Mello acaba construindo um "regime" para o direito público significativamente mais impositivo - e mais propenso ao exercício autoritário - do que aquele teorizado por Cirne Lima.

Ainda que a proposta de Celso Antônio Bandeira de Mello forneça algo como uma "ressignificação positivista" do regime da administração pública proposto por Cirne Lima, e ainda que isso resulte, como argumentou-se, em uma construção significativamente mais autoritária do direito público, salienta-se, já a título de conclusão, duas linhas que parecem definir as duas antípodas. Linhas que, segundo a partir da análise, fornecem a ideia mais abstrata e mais geral do "regime jurídico" do direito público brasileiro. As bases teóricas disso que aqui se chamou, simpaticamente, de "regime jurídico à brasileira".

I. O regime de direito público possui um tipo específico de base normativa, marcado pela impessoalidade, o que significa a indisponibilidade dos interesses públicos, quer pela administração, quer pelos administrados. Interesses públicos não podem ser transacionados, pactuados ou mesmo definidos por seus titulares (os cidadãos). Isso acontece seja porque tais interesses se encontrem subordinados ao bem público (leitura jusnaturalista), seja porque esses interesses se encontrem, na leitura positivista, vinculados à "vontade da lei", que pode ser tanto a vontade do legislador (ato vinculado) quanto a vontade do administrador (ato discricionário). O essencial, aqui, é que tais interesses constituem a baliza da administração pública, que age em nome deles impondo-se sobre os interesses privados.

II. O regime de direito público importa sempre a mesma sequência lógica de atuação. Em primeiro lugar, identifica- 
se uma atividade como administrativa (seja pelo critério da utilidade pública, na leitura jusnaturalista, seja pelo critério da atribuição formal, na leitura positivista). Em segundo lugar, identifica-se a atividade administrativa a uma "atividade do Estado". Em terceiro lugar, identifica-se a atividade do Estado à organização do Estado, o que reduz o "Estado" à administração pública formal, burocracia regida pela hierarquia e pela especialização. Em quarto lugar, identifica-se a administração pública formal ao arquétipo estatal de "pessoa jurídica soberana", de onde a administração colheria as "prerrogativas da soberania" que permitiriam sua atuação impositiva e unilateral. Em quinto lugar - e esse é o passo conclusivo - são encadeadas as atividades administrativas, o poder soberano do Estado e a organização administrativa formal, fazendo surgir um regime jurídico marcado pela hierarquia, pela sujeição e pela exorbitância.

5. Conclusão: regime de direito público ou regime da pessoa administrativa?

No tópico anterior, procurou-se demonstrar que as construções de Cirne Lima e de Celso Antônio Bandeira de Mello chegam, por vias diferentes, a certo modelo teórico de "regime jurídico de direito público" que o aparta, de um modo geral, tanto dos indivíduos que vivem sob sua regulação, quanto do direito comum, onde valem as relações paritárias e horizontais. Vale notar, nesta conclusão, que essas duas características (supremacia e verticalidade) são, apesar de seus diversos problemas teóricos e operacionais, o que determina a originalidade do conceito genuinamente brasileiro de "regime jurídico de direito público", dado com o qual iniciou-se este artigo. ${ }^{24}$

Causa, ainda assim, alguma estranheza, que se aceite, com tamanha naturalidade que este seja o único conteúdo possível da ideia de um "regime jurídico de direito público". Isso é especialmente notável, por exemplo, quando se percebe que, em uma sociedade democratizada, como a brasileira, não se inclui, neste tópico conceitual, qualquer menção ao arranjo, à participação dos cidadãos na feitura e no controle das normas jurídicas, até mesmo como conteúdo normativo da ideia de impessoalidade, superando uma leitura de indisponibilidade que parece supor que os indivíduos não tenham a capacidade ou mesmo o direito de definir, autonomamente, seus próprios interesses (ALMEIDA, 2012b, p. 112). Outra fonte importante de perplexidade é a aceitação, quase que automática, na literatura brasileira sobre regime jurídico de direito público, de que o Estado é, conceitual

24 Para uma síntese desses problemas, muito bem referidos como "maldição do regime único", v. Marques Neto (2009). 
e necessariamente, uma pessoa jurídica, que coincide com a organização administrativa em sentido subjetivo, como se no plano da constitucionalização não se operasse uma diluição das funções administrativas para além da organização formal da administração pública, e uma expansão da lógica das obrigações, constrangimentos e compromissos estatais para além da burocracia pública (LOUGHLIN, 2016, p. 464).

Esses dois pontos parecem mostrar, com razoável clareza, tanto a potencialidade quanto a necessidade de uma redefinição da ideia de regime jurídico de direito público no Brasil. Em um quadro de incremento da reivindicação global por participação pública na formulação e monitoramento de decisões governamentais, de progressiva desburocratização do Estado, e de erosão do monopólio normativo dos Estados nacionais, é significativa a necessidade de enquadramento, em um regime "vinculante" e pautado por "obrigações jurídicas públicas", os agentes que se encontrem em posição de internalizar, em suas atividades, predicados objetivos (standards) normalmente associados à atuação estatal, como a impessoalidade, a igualdade, a publicidade, a governança democrática, a representatividade, a estabilidade das posições subjetivas e a promoção da autonomia individual.

A resposta adequada a esse tipo de demanda não será, contudo, um regime jurídico lastreado na organização administrativa burocrática, na supremacia da administração e na disciplina do administrado. Funções constitucionais e obrigações jurídicas dessa latitude pressupõem o alargamento do próprio conceito de Estado, que já não pode ser reduzido às pessoas jurídicas integrantes da administração pública, nem vulgarizado como mero indicador de "poderes soberanos incontrastáveis". Uma crítica consequente aos usos que o direito público tem dado ao conceito de Estado é capaz de implodir as linhas básicas do "regime jurídico à brasileira". Afinal, prerrogativas, hierarquia e exorbitância pressupõem a existência de uma pessoa jurídica superior, confundida tanto com o Estado quanto com a administração pública, na forja de um estranho amálgama conceitual que só tem a instigar uma prática jurídica irrefletida e autoritária.

No sentido de "drive", que é a melhor tradução, em inglês, para a expressão latina regis mina, o direito público (ius publicum) não é mais do que uma parte do direito, do arranjo jurídico de determinada comunidade (civitas), ocupada diretamente com a regulação difusa e participativa de aspectos da vida civil tidos por relevantes pelos cidadãos. Ironicamente, em vez de importar do direito civil romano a noção de administratio, talvez seja tempo de reler a summa divisio, para assim reconduzir o direito público ao direito comum.

São Paulo, primavera de 2017. 


\section{Referências}

ALMEIDA, Fernando Dias Menezes de. Contrato administrativo. São Paulo: Quartier Latin, 2012a. ALMEIDA, Fernando Dias Menezes de. Formação da teoria do direito administrativo no Brasil. São Paulo: Quartier Latin, 2015.

ALMEIDA, Fernando Dias Menezes. Princípio da impessoalidade. In: MARRARA, Thiago (org.). Princípios de direito administrativo: legalidade, segurança jurídica, impessoalidade, publicidade, motivação, eficiência, moralidade, razoabilidade, interesse público. São Paulo: Atlas, 2012b. p. 109118.

BANDEIRA DE MELLO, Celso Antônio. Curso de direito administrativo. 29. ed. São Paulo: Malheiros, 2012.

BANDEIRA DE MELLO, Celso Antônio. Natureza e regime jurídico das autarquias. São Paulo: Revista dos Tribunais, 1968.

BARROSO, Luís Roberto. A constitucionalização do direito e suas repercussões no âmbito administrativo. In: ARAGÃO, Alexandre Santos de; MARQUES NETO, Floriano de Azevedo (coord.). Direito administrativos e seus novos paradigmas. Belo Horizonte: Fórum, 2012. p. 31-63.

BEAUD, Olivier. The State. Sorbonne-Assas Law Review, Paris, v. 4, n. 1, p. 1-48, 2015.

COUTO, Cláudio Gonçalves; ARANTES, Rogério Bastos. Constituição, governo e democracia no Brasil. Revista Brasileira de Ciências Sociais, São Paulo, v. 21, n. 61, p. 41-62, 2006.

DI PIETRO, Maria Sylvia Zanella. Transformações do direito administrativo. Revista de Direito da Administração Pública, Rio de Janeiro, a. 1, v. 1, n. 2, p. 185-211, jul./dez. 2016.

DOMAT, Jean. Les lois civiles dans leur ordre naturel. Orange: Wentworth Press, 2019.

GABARDO, Emerson; HACHEM, Daniel Wunder. O suposto caráter autoritário da supremacia do interesse público e das origens do direito administrativo: uma crítica da crítica. In: DI PIETRO, Maria Sylvia Zanella; RIBEIRO, Carlos Vinícius Alves (coord.). Supremacia do interesse público e outros temas relevantes do direito administrativo. São Paulo: Atlas, 2010. p. 13-66.

JAMIN, Christophe; MELLERAY, Fabrice. Droit civil et droit administratif: dialogue(s) sur un modèle doctrinal. Paris: Dalloz, 2018.

LIMA, Ruy Cirne. Direito administrativo e direito privado. Revista de Direito Administrativo, Rio de Janeiro, v. 26, p. 19-33, 1951.

LIMA, Ruy Cirne. Introdução ao estudo do direito administrativo brasileiro. Porto Alegre: Livraria do Globo, 1942.

LIMA, Ruy Cirne. O conceito fundamental do direito administrativo. Revista de Direito Administrativo, Rio de Janeiro, v. 12, p. 59-64, 1948. 
LIMA, Ruy Cirne. Preparação à dogmática jurídica. 2. ed. Porto Alegre: Livraria Sulina, 1958.

LIMA, Ruy Cirne. Princípios de direito administrativo. 7. ed. rev. e reelab. por Alberto Pasqualini. São Paulo: Malheiros, 2007.

LOUGHLIN, Martin. Foundations of public law. Oxford: Oxford University Press, 2016.

MARQUES NETO, Floriano Peixoto de Azevedo. A bipolaridade do direito administrativo e sua superação. In: SUNDFELD, Carlos Ari; JURKSAITIS, Guilherme Jardim (org.). Contratos públicos e direito administrativo. São Paulo: Malheiros, 2015. p. 353-415.

MARQUES NETO, Floriano Peixoto de Azevedo. Do contrato administrativo à administração contratual. Revista do Advogado, São Paulo, v. 29, n. 107, p. 74-82, dez. 2009.

MARQUES NETO, Floriano Peixoto de Azevedo. Regulação estatal e interesses públicos. São Paulo: Malheiros, 2002.

MAYER, Otto. Derecho administrativo alemán. Traducción directa del original francés por Horacio H.Heredia y Ernesto Krotoschin. Buenos Aires: Editorial Depalma, 1949.

MEDAUAR, Odete. A processualidade no direito administrativo. São Paulo: Revista dos Tribunais, 1993.

SARMENTO, Daniel. Supremacia do interesse público? As colisões entre direitos fundamentais e interesses da coletividade. In: ARAGÃO, Alexandre Santos de; MARQUES NETO, Floriano Peixoto de Azevedo (coord.). Direito administrativo e seus novos paradigmas. Belo Horizonte: Fórum, 2008.

SCHIOPPA, Antonio Padoa. História do direito na Europa: da idade média à idade contemporânea. São Paulo: Martins Fontes, 2014.

SCHIRATO, Vitor Rhein. Livre iniciativa nos serviços públicos. Belo Horizonte: Fórum, 2012.

SILVA, Luis Virgílio Afonso da. O conteúdo essencial dos direitos fundamentais e a eficácia das normas constitucionais. Revista de Direito do Estado, Rio de Janeiro, v. 1, n. 4, p. 23-51, out./dez. 2006.

SUNDFELD, Carlos Ari. Direito administrativo para céticos. São Paulo: Malheiros, 2012.

TOMÁS DE AQUINO. Suma teológica. São Paulo: Loyola, 2005. v. 1.

TROPER, Michel. A filosofia do direito. Tradução Ana Deiró. São Paulo: Martins Fontes, 2008. 